\title{
NEW DATA ON THE $\delta$ SCUTI STAR 44 TAURI
}

\author{
N. MORGULEFF \\ Institut d'Astrophysique, Paris, France \\ V. OSKANIAN \\ Byurakan Observatory, Armenian S.S.R, U.S.S.R. \\ and \\ B. RUTILY and A. TERZAN \\ Observatoire de Lyon, Saint-Genis-Laval, France
}

\begin{abstract}
Photometric and spectroscopic observations were made by Oskanian and Terzan (1974) on the 40-cm telescope at Byurakan Observatory and by Morguleff $e$ al . simultaneously at the $80-\mathrm{cm}$ photometric telescope and the Coudé Spectrograph of the 152-cm telescope of the Observatoire de Haute Provence.

These and earlier published observations were searched for periodicities, especially those in long nights $(n=47)$. The 33 values found for a short period are plotted in the histogram (Figure 1). The period seems to oscillate around a value of about 0.13 days. The present data do not allow a search for long periods.
\end{abstract}

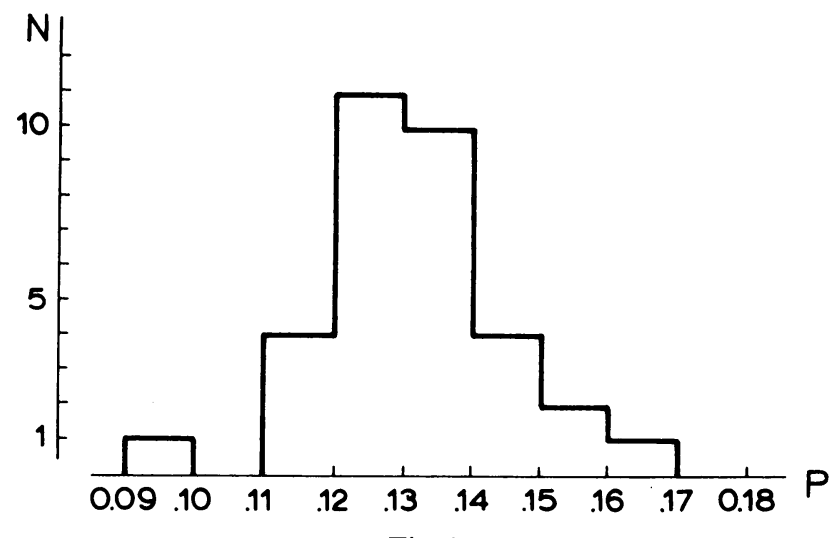

Fig. 1.

\section{References}

Oskanian, V. and Terzan, A.: 1974, Info. Bull. Var. Stars, No. 899.

Morguleff, N., Rutily, B., and Terzan, A.: Unpublished observations.

\section{REMARK}

M. S. Frolov drew the attention to an error in the absolute magnitudes of dwarf Cepheids (AI Velorum stars) as given by Baglin et al. (1973); the $M_{V}$ taken over from McNamara (1965) had to be corrected by $+1^{m} 4$ as already stated by McNamara. Independently a period-luminosity relation $M_{V}=$ $-1 m 3-4.5 \log P$ was derived (Frolov, 1971). 
References

Baglin, A., Breger, M., Chevalier, C., Hauck, B., Le Contel, J. M., Sareyan, J. P., and Valtier, J. C.: 1973, Astron. Astrophys. 23, 221.

Frolov, M. S.: 1971, Astron. Circ. USSR, No. 619, 4.

McNamara, D. H.: 1965, Kl. Veröff. Bamberg, 40, 111. 